\title{
INTUBACINIO VAMZDELIO MANŽETÉS SLE்GIS BENDRŲJŲ ANESTEZIJŲ METU: AR PRAKTIKOJE JIS ATITINKA NORMĄ?
}

\author{
Miglè Siderkevičiūtė ${ }^{1}$, Karolina Buožyte் ${ }^{2}$, Andrius Macas ${ }^{1}$ \\ ${ }^{1}$ Lietuvos sveikatos mokslu universiteto Medicinos akademijos Anesteziologijos klinika, \\ ${ }^{2}$ Lietuvos sveikatos mokslu universiteto Medicinos fakultetas
}

\begin{abstract}
Raktažodžiai: bendroji anestezija, manžetès slègis, komplikacijos.
\end{abstract}

\begin{abstract}
Santrauka
Rekomenduojamas intubacinio vamzdelio manžetės slègis yra $20-30 \mathrm{~cm} \mathrm{H}_{2} \mathrm{O}$. Jo svarbą atspindi kvèpavimo takų komplikacijų, galimų esant netinkamam manžetès slègiui, gausa. Dažnai šis slègis bendrosios anestezijos metu viršija rekomenduojamas normos ribas. Trachejjos gleivinès kraujotaka sutrikdoma, kai intubacinio vamzdelio manžetès slègis viršija 30 $\mathrm{cm} \mathrm{H}_{2} \mathrm{O}$. Per didelis slègis gali sukelti tokių komplikacijų, kaip trachèjos gleivinès pažeidimas, kraujavimas iš pažeistos gleivinès, balso klosčiu paralyžius, trachejjos stenozè, tracheomaliacija, trachejos perforacija. Esant per mažam manžetès slègiui, kyla aspiracijos skrandžio turiniu, aspiracinio pneumonito ar aspiracinès pneumonijos rizika.

Tyrimo tikslas. Nustatyti ir ịvertinti intubacinio vamzdelio manžetès slègị Lietuvos sveikatos mokslų universiteto ligoninės Kauno klinikų (LSMUL KK) Anesteziologijos klinikoje bendrujų anestezijų metu. Metodika. Atliktas perspektyvusis aklasis tyrimas, $i$ kuri ịtrauktas 31 pacientas. Pacientų intubacinio vamzdelio manžetès slègis matuotas manometru, rinkti duomenys apie pacientų demografinius rodiklius, ASA, Mallampati klases, vidutinę operacijos trukmę bei naudoto intubacinio vamzdelio dydį. Gauti duomenys apskaičiuoti Excel 2010 skaičiuoklejje ir pateikti lentelių ir grafikų pavidalu.

Rezultatai. Išmatuotų manžečių slègių vidurkis $75,52 \mathrm{~cm} \mathrm{H}_{2} \mathrm{O}$ (slègiui svyruojant tarp 30-120 cm $\mathrm{H}_{2} \mathrm{O}$ ). Intubacinių vamzdelių manžetès slègis 30 pacientų $(96,77 \%)$ buvo didesnis, nei rekomenduojama norma ( $>30 \mathrm{~cm} \mathrm{H}_{2} \mathrm{O}$ ). Šios grupès slègių vidurkis $77,03 \mathrm{~cm} \mathrm{H}_{2} \mathrm{O}\left(31-120 \mathrm{~cm} \mathrm{H}_{2} \mathrm{O}\right)$. Tik 1 (3,23 \%) iš stebètų pacientų intubacinio vamzdelio slègis buvo normos ribose $\left(20-30 \mathrm{~cm} \mathrm{H}_{2} \mathrm{O}\right)$.
\end{abstract}

Išvados. LSMUL KK Anesteziologijos klinikoje bendrujų anestezijų metu intubacinio vamzdelio manžetès slègis neatitinka rekomenduojamos normos. Daugumos tyrime dalyvavusių pacientų manžetès slègis buvo didesnis, nei rekomenduojamas.

\section{Ivadas}

Pirmoji aprašyta endotrachèjinè intubacija buvo atlikta Hipokrato (380 - 460 m. pr. Kr.) [3]. Šiuo metu endotrachejjinè intubacija yra viena iš svarbiausių procedūrų šiuolaikineje anestezijoje. Manoma, jog vien tik JAV per metus atliekama 13-20 milijonų intubacijų [8].

Dabartineje anestezijoje naudojami intubaciniai vamzdeliai ženkliai skiriasi nuo pirmujų prototipų. Šiuo metu naudojami intubaciniai vamzdeliai gaminami iš polivinilchlorido, kurie turi didelio tūrio - mažo slègio manžetes (1 pav.), prisitaikančias prie trachèjos linkių ir sukeliančias mažesni trachëjos gleivinès pažeidimą, nei prieš tai naudoti, iš standžios gumos pagaminti vamzdeliai, turintys mažo tūrio didelio slègio manžetes $[3,5,6]$.

Pagrindinès intubacinio vamzdelio manžetės funkcijos yra dvi: išvengti oro nuosruvio, esant teigiamo slègio ventiliacijai ir užkirsti kelią skrandžio turinio aspiracijai ị kvépavimo takus [1]. Intubacinio vamzdelio manžetès slėgis turi būti kuo mažesnis, kad nesutrikdytų trachèjos gleivinès kraujotakos, tačiau tuo pat metu būtų išvengta skrandžio turinio aspiracijos ị kvépavimo takus bei oro nuosruvio, esant teigiamo slègio ventiliacijai $[1,4]$.

Trachèjos gleivinès kraujotaka sutrikdoma, kai intubacinio vamzdelio manžetès slègis viršija $30 \mathrm{~cm} \mathrm{H}_{2} \mathrm{O}$, todèl gali ịvykti gleivinès išemija, nekrozè, kuri skatina uždegimą, randinio audinio formavimąsi bei trachèjos stenozę (2 pav.) $[1,7]$. Daugelis šių komplikacijų prasideda dèl užsitęsusios, ilgesnès kaip 7 dienų, intubacijos. Anksčiau trachèjos stenozė išsivystydavo 1 proc. pacientų, kurie buvo intubuoti ilgą laiką, tačiau, naudojant mažo slègio - didelio tūrio manžetes, stenozių dažnis sumažejo 10 kartų. Vis dèlto pasitaiko trachejjos stenozės atvejų ir po trumpesnès nei 24 
val. intubacijos [10]. Rekomenduojamas manžetès slëgis yra 20-30 $\mathrm{cm} \mathrm{H}_{2} \mathrm{O}$. Slègiui viršijus $30 \mathrm{~cm} \mathrm{H}_{2} \mathrm{O}$, stebima sumažejusi trachèjos gleivinès kraujotaka, o viršijus $50 \mathrm{~cm}$ $\mathrm{H}_{2} \mathrm{O}$, ji gali visai išnykti [3]. Didesnis slègis tenka trachèjos priekinei bei šoninei kremzlinėms sienelėms, mažiausias - užpakalinei membraninei sienelei, kurioje gleivinès kraujotaka sutrikdoma mažiausiai [3]. Slègiui perkopus trachèjos kapiliarų perfuzijos galimybes, gleivinès kraujotaka sutrikdoma, todèl pacientai po bendrụjų endotrachèjinių anestezijų skundžiasi gerklès skausmu, užkimimu, kosuliu (2 pav.) [2]. Galimos tokios komplikacijos, kaip trachejos gleivinès pažeidimas, kraujavimas iš pažeistos gleivinès, balso klosčių paralyžius, trachèjos stenozè, tracheomaliacija, trachëjos perforacija, tačiau tikslus komplikacijų dažnis nèra žinomas $[1,3,5]$. Priešingai, esant per mažam manžetès slègiui, gali ịvykti aspiracija skrandžio turiniu, išsivys-

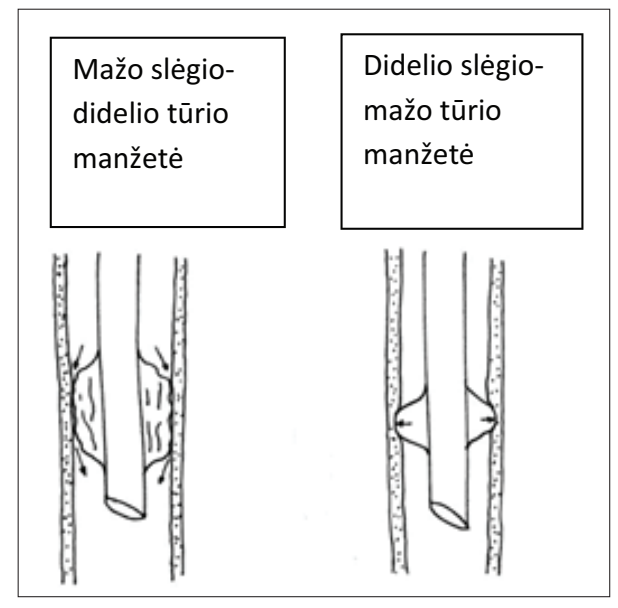

1 pav. Endotrachẻjinių vamzdelių manžečių skirtumai

Šaltinis: autoriu adaptuotas pav. [6].

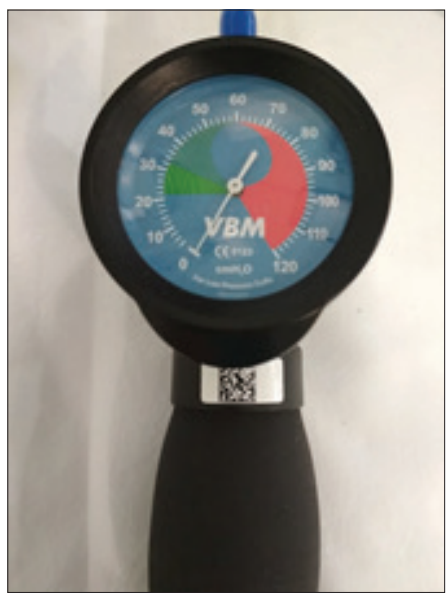

3 pav. VBM manometras tyti aspiracinis pneumonitas ar aspiracinè pneumonija [2].

Slègis intubacinio vamzdelio manžetèje priklauso nuo daugelio veiksnių: pripūsto oro tūrio, manžetės dydžio santykio su trachejjos spindžiu, intratorakalinio spaudimo, paciento galvos padèties, kūno temperatūros [3]. Slègis taip pat gali kisti bendrujų anestezijų metu, kai naudojamas azoto suboksidas [9].

Literatūros šaltiniuose aprašoma ịvairi endotrachẻjinio vamzdelio manžetės pripūtimo technika. Minimalaus nuosruvio technika, kai manžetė pripučiama tiek, kad ịkvėpimo gale auskultuojant girdimas minimalus nuosruvis. Minimalus okliuzinis spaudimas - manžetė pripučiama tiek, kad teigiamo slègio ventiliacijos metu įkvėpimo pabaigoje auskultuojant visiškai negirdima nuosruvio. Iš anksto numatyto oro kiekio pripūtimo technika, kai pripučiamas numatytas oro kiekis, paprastai pakanka $2-4 \mathrm{ml}$ oro pasiekti manžetès

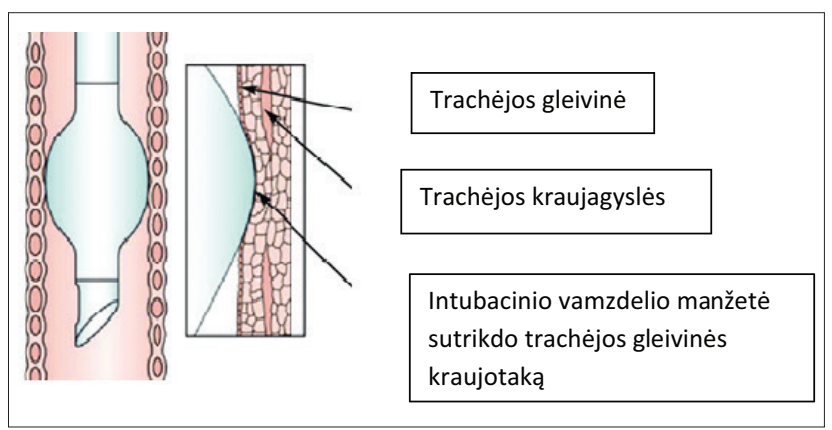

2 pav. Intubacinio vamzdelio manžetės poveikis trachèjos gleivinès kraujotakai

Šaltinis: autoriu adaptuotas pav.[3]

1 lentelè. Tiriamujų demografiniai rodikliai

\begin{tabular}{|c|c|c|}
\hline Kintamieji & $\begin{array}{l}\text { Vamzdelio } \\
\text { dydis } 7,0 \\
(100 \%)\end{array}$ & $\begin{array}{c}\text { Vamzdelio dydis }>7,0 \\
(7,5-93,75 \% \\
8,0-6,25 \%) \\
\end{array}$ \\
\hline Tiriamujų skaičius & $15(48 \%)$ & $16(52 \%)$ \\
\hline Lytis & Moterys $(100 \%)$ & Vyrai $(100 \%)$ \\
\hline Amžiaus vidurkis & 65,8 metai & 52,4 metai \\
\hline \multirow{3}{*}{$\begin{array}{l}\text { Mallampati skalė } \\
\text { (tiriamujų pasiskirs- } \\
\text { tymas \%) }\end{array}$} & $1-(30 \%)$ & $1-(62,5 \%)$ \\
\hline & $2-(33,33 \%)$ & $2-(31,25 \%)$ \\
\hline & $3-(6,67 \%)$ & $3-(6,25 \%)$ \\
\hline \multirow{4}{*}{$\begin{array}{l}\text { ASA skalė } \\
\text { (tiriamujų pasiskirs- } \\
\text { tymas \%) }\end{array}$} & $1-(0 \%)$ & $1-(18,75 \%)$ \\
\hline & $2-(33,33 \%)$ & $2-(18,75 \%)$ \\
\hline & $3-(60 \%)$ & $3-(62,5 \%)$ \\
\hline & $4-(6,67 \%)$ & \\
\hline $\begin{array}{l}\text { Vidutinè operacijos } \\
\text { trukmė }\end{array}$ & 2,3 val. & 2,7 val. \\
\hline
\end{tabular}


slėgio normą arba palpacijos technika. Šiuo metu tiksliausia ir labiausiai rekomenduojama technika - tęstinis manžetės slègio matavimas manometru $[1,3,7]$. Ivvairi literatūra ir atlikti tarptautiniai tyrimai parodo, jog intubacinio vamzdelio manžetès slègis bendrosios anestezijos metu viršija rekomenduojamas normas [1], todèl šio tyrimo tikslas yra ištirti, ar LSMUL KK Antesteziologijos klinikoje bendrujų anestezijų metu intubacinio vamzdelio manžetès slègis atitinka normą.

Tyrimo tikslas - nustatyti ir ivertinti intubacinio vamzdelio manžetės slègi LSMUL KK Anesteziologijos klinikoje bendrujų anestezijų metu.

\section{Tyrimo medžiaga ir metodai}

Atliktas perspektyvusis aklasis tyrimas LSMUL KK Anesteziologijos klinikoje 2019 m. gegužès - rugpjūčio mènesiais. Buvo įtraukti ir planines, ir skubiąsias operacijas patyrę pacientai. Operacijos pasirinktos atsitiktine tvarka. Apie duomenų rinkimo laiką operacinių personalas nebuvo informuotas. Intubacinių vamzdelių manžečių slègį matavo vienas tyrèjas. Siekiant duomenų tikslumo, manžetès slègis tą pačią dieną toje operacinèje kitų operacijų metu nebuvo matuojamas. Vienos operacijos metu slègis matuotas vieną kartą. Intubacinio vamzdelio manžetės slègis buvo matuojamas VBM firmos manometru (3 pav.). Remiantis rekomendacijomis, buvo laikoma, kad manžetès slègio norma yra 20-30 $\mathrm{cm} \mathrm{H}_{2} \mathrm{O}$. Didžiausias tyrime naudoto VBM manometro matuojamas slègis yra $120 \mathrm{~cm} \mathrm{H}_{2} \mathrm{O}$, todèl mūsų tyrime slègis, didesnis nei $120 \mathrm{~cm} \mathrm{H}_{2} \mathrm{O}$, registruotas kaip $120 \mathrm{~cm} \mathrm{H}_{2} \mathrm{O}$. Pastebejjus, jog slègis viršija $30 \mathrm{~cm} \mathrm{H}_{2} \mathrm{O}$ ribą, pasitarus su operacinès atsakingu gydytoju anesteziologu, slègis buvo sumažintas iki normos. Surinkti duomenys apie pacientų demografinius rodiklius, ASA, Mallampati klases, vidutinę operacijos trukmę bei naudoto intubacinio vamzdelio dydį. Gautieji duomenys buvo apskaičiuoti Excel 2010 skaičiuokleje. Statistica 12 (Statsoft, JAV) buvo naudojamas atlikti statistinę duomenų analizę. Duomenys pateikti lentelių ir grafikų pavidalu.

\section{Tyrimo rezultatai}

Iš viso ị tyrimą ịtrauktas 31 pacientas. Iš jų 15 (48 \%) moterų ir $16(52 \%)$ vyrų. Bendras pacientų vidutinis amžius -58 metai. Detaliau pacientų demografiniai rodikliai pateikiami 1 lentelejje. Išmatuoto manžečiu slègio vidurkis $-75,52$

2 lentelè. Manžečių slègio ir vamzdelio dydžio santykis

\begin{tabular}{|l|l|l|l|}
\hline Vamzdelio dydis & $\mathbf{7 , 0} \mathbf{~ m m}$ & $\mathbf{7 , 5} \mathbf{~ m m}$ & $\mathbf{8} \mathbf{~ m m}$ \\
\hline Slègis $<20 \mathrm{~cm} \mathrm{H}_{2} \mathrm{O}$ & 0 & 0 & 0 \\
\hline Slègis $20-30 \mathrm{~cm} \mathrm{H}_{2} \mathrm{O}$ & $1(6,67 \%)$ & 0 & 0 \\
\hline Slègis $>30 \mathrm{~cm} \mathrm{H}_{2} \mathrm{O}$ & $14(93,33 \%)$ & $15(100 \%)$ & $1(100 \%)$ \\
\hline Iš viso tiriamujų & $15(48,39 \%)$ & $15(48,39 \%)$ & $1(3,22 \%)$ \\
\hline
\end{tabular}

cm $\mathrm{H}_{2} \mathrm{O}$ (slègiui svyruojant nuo 30 iki $120 \mathrm{~cm} \mathrm{H}_{2} \mathrm{O}$ ). Išmatuotas manžečių slègis nuo intubacinio vamzdelio dydžio nepriklausė (2 lentelè). Moteru grupejje vidutinis manžetės slègis buvo 83,73 $\mathrm{cm} \mathrm{H}_{2} \mathrm{O}$, vyru - 79,69 $\mathrm{cm} \mathrm{H}_{2} \mathrm{O}$ (4 pav.). Intubacinių vamzdelių manžetès slègis 30 pacientų $(96,77 \%)$ buvo didesnis, nei norma $\left(>30 \mathrm{~cm} \mathrm{H}_{2} \mathrm{O}\right)$. Šios grupès slègių vidurkis $77,03 \mathrm{~cm} \mathrm{H}_{2} \mathrm{O}\left(31-120 \mathrm{~cm} \mathrm{H}_{2} \mathrm{O}\right)$. Tik $1(3,23 \%)$ iš stebètų pacientų intubacinio vamzdelio slègis buvo normos ribose $\left(20-30 \mathrm{~cm} \mathrm{H}_{2} \mathrm{O}\right)$.

\section{Diskusija}

Kasdienėje praktikoje daugèjant ịvairių chirurginių, instrumentinių procedūrų, kurių metu reikalinga anestezija, daugejja ir bendrujų endotrachèjinių anestezijų bei jų sukeliamų komplikacijų $[1,3,5]$. Nors endotrachejjinio vamzdelio manžetès slègio matavimas neįtrauktas nei ị Amerikos (ASA), nei ị Europos anesteziologų draugijos (ESA) stebėsenos gaires, siekiant sumažinti komplikacijų dažnį, vertetų įtraukti manžetės slègio matavimą manometru ị kasdienę praktiką.

JAV atliktame tyrime intubacinio vamzdelio slègių vidurkis buvo $35,3 \mathrm{~cm} \mathrm{H}_{2} \mathrm{O}$ [1]. Indijos valstybineje mokomojoje ligoninejje atlikto tyrimo metu užfiksuotas vidutinis $27,07 \mathrm{~cm}$ $\mathrm{H}_{2} \mathrm{O}$ vamzdelio slègis [1]. Keiptauno akademinèje ligoninèje išmatuotas intubuotų pacientų slègių vidurkis siekè $25 \mathrm{~cm}$ $\mathrm{H}_{2} \mathrm{O}$ [1]. Danijoje atliktas tyrimas nustatè slègių vidurkị normos ribose $-30 \mathrm{~cm} \mathrm{H}_{2} \mathrm{O}$ (nuo 8 iki $100 \mathrm{~cm} \mathrm{H}_{2} \mathrm{O}$ ) [1]. Mūsų tyrime išmatuotas endotrachèjinių vamzdelių manžečių slègio vidurkis buvo 75,52 $\mathrm{cm} \mathrm{H}_{2} \mathrm{O}$. Mūsų tyrime 96,77 proc. pacientų išmatuoti slègiai viršijo $30 \mathrm{~cm} \mathrm{H}_{2} \mathrm{O}$ ribą, lyginant juos su 50 proc. pacientų JAV tyrime, 45 proc. Danijos tyrime, 26,2 proc. Indijoje ir 23 proc. Keiptaune [1]. Verta pažymèti, jog išvardytuose tyrimuose visi anesteziologai buvo supažindinti su tyrimu ir jo metodika. Mūsų atliktame tyrime anesteziologai nebuvo informuoti, kuriomis dienomis bus matuojami intubacinių vamzdelių slėgių rodikliai ir renkami duomenys.

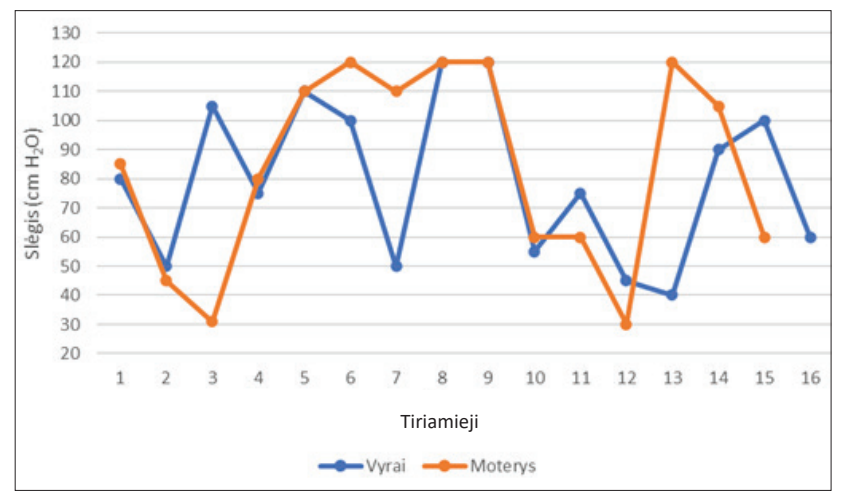

4 pav. Tiriamųjų intubacinio vamzdelio manžetės slègis bendrosios anestezijos metu 
Kitu šalių tyrimuose dokumentuota, jog nèra statistiškai reikšmingos sąsajos tarp intubacinio vamzdelio išpūtimo technikos ir jo viduje išmatuojamo slègio [1]. Šio tyrimo metu bendrosios anestezijos ir intubacijos technika bei naudotos pagalbinès priemonès priklausė nuo anesteziologo, atsakingo už pacientą, nuožiūros. Anksčiau minètuose tyrimuose nustatyta, jog nèra priklausomumo tarp vamzdelio dydžio ir išmatuojamo slègio [1].

C. Döğer ir kitų autorių atliktame tyrime nustatyta, jog dažniausiai intubacinio vamzdelio manžeteje didesnis slègis sudaromas norint išvengti oro nuosruvio ir nepakankamos ventiliacijos. Labiau patyrę gydytojai pasiekia geresnių slègio reguliavimo rezultatu ir geba palaikyti tinkamą slègi esant ir mažam, ir dideliam oro tūriui [2]. Kitame tyrime pastebèta, jog tinkamas slègio ir oro tūrio palaikymas didejjo, didejjant anesteziologų stažui [2]. Darome išvadą, jog keliant darbuotojų kompetenciją, plečiant teorines žinias ir formuojant praktinius gebejjimus, ilgainiui pasiekiama geresnių intubacinio vamzdelio manžetès slègio palaikymo rezultatų.

\section{Išvados}

1. LSMUL KK Anesteziologijos klinikoje bendrujų anestezijų metu intubacinio vamzdelio manžetès slègis neatitinka rekomenduojamos normos.

2. Daugumos tyrime dalyvavusių pacientų manžetès slègis buvo didesnis, nei rekomenduojamas.

3. Bendrujų endotrachèjinių anestezijų metu manžetès slègis nematuojamas manometru, o pasikliaunama kitais manžetès slègio vertinimo metodais.

\section{Literatūra}

1. Gilliland L, Perrie H, Scribante J. Endotracheal tube cuff pressures in adult patients undergoing general anaesthesia in two Johannesburg academic hospitals. Southern African Journal of Anaesthesia and Analgesia 2015; 21:3, 81-84.

https://doi.org/10.1080/22201181.2015.1056504

2. Özcan ATD, Döğer C, But A, Kutlu I, Aksoy SM. Comparison of endotracheal tube cuff pressure values before and after training seminar. J Clin Monit Comput 2018;32:527-531. https://doi.org/10.1007/s10877-017-0046-7

3. Sultan P, Carvalho B, Rose BO, Cregg R. Endotracheal tube cuff pressure monitoring: a review of the evidence. Article in Journal of Perioperative Practice 2011;21(11):379-86. https://doi.org/10.1177/175045891102101103

4. Sole ML, Su X, Talbert S, Penoyer DA, Kalita S, Jimenez E, et al. Evaluation of an intervention to maintain endotracheal tube cuff pressure within therapeutic range. Am J Crit Care 2011;20(2),109-118. https://doi.org/10.4037/ajcc2011661

5. Khan MU, Khokar R, Qureshi S, Zahrani TA, Aqil M, Shiraz M. Measurement of endotracheal tube cuff pressure: instrumental versus conventional method. Saudi J Anaesthesia
2016;10(4):428-431.

https://doi.org/10.4103/1658-354X.179113

6. Endotrachèjiniai vamzdeliai. https://aam.ucsf.edu/endotracheal-tubes

7. Feng TR, Ye Y, Doyle DJ. Critical importance of tracheal tube cuff pressure management. World J Anesthesiology 2015;4(2):10-12.

https://doi.org/10.5313/wja.v4.i2.10

8. Lovett PB, Flaxman A, Stürmann KM. The insecure airway: a comparison of knots and commercial devices for securing endotracheal tubes. BMC Emerg Med 2006;6(7).

https://doi.org/10.1186/1471-227X-6-7

9. Morgan \& Mikhail's. Clinical anesthesiology. New York, 2013;320-322.

10. Abdelfattah A, Stratakos GK. Long-term complications of tracheal intubation. Tracheal Intubation 2018;89-112.

\section{ENDOTRACHEAL TUBE CUFF PRESSURE DURING GENERAL ANAESTHESIA: \\ DOES IT MEET THE NORM IN PRACTICE?}

\section{Siderkevičiūtė, K. Buožytė, A. Macas}

Keywords: general anaesthesia, endotracheal tube cuff pressure, complications.

Summary

It is recommended that endotracheal tube cuff pressure is between 20 and $30 \mathrm{cmH}_{2} \mathrm{O}$. The importance of endotracheal tube cuff pressures is highlighted by the spectrum of airway complications that can occur with incorrect cuff pressures. It often exceeds the recommended range during anaesthesia. Tracheal mucosal blood flow is disrupted when cuff pressure exceeds $30 \mathrm{cmH}_{2} \mathrm{O}$, complications such as tracheal mucosal damage, bleeding from damaged mucosa, vocal cord paralysis, tracheal stenosis, tracheomalacia, tracheal perforation may occur. On the other hand, cuff pressures that are too low place the patient at risk for aspiration of gastric contents and consequently, aspiration pneumonitis and pneumonia.

The aim of the study was to determine and evaluate the pressure of endotracheal tube cuff at the LSMUL KK Clinic of Anaesthesiology during general anaesthesia.

Methodology. A prospective blind study was performed. 31 patients were included. For each patient the tube cuff pressure was measured with a manometer, data was collected on patient demographics, ASA, Mallampati classes, mean duration of surgery, and size of the intubation tube used. The obtained data was calculated in a Excel 2010 spread sheet and presented in the form of tables and graphs.

Results. The average pressure of the measured cuffs is 75,52 $\mathrm{cmH}_{2} \mathrm{O}$ (pressure range $30-120 \mathrm{cmH}_{2} \mathrm{O}$ ). Endotracheal cuff pressures were above normal $\left(>30 \mathrm{cmH}_{2} \mathrm{O}\right)$ in $30(96,77 \%)$ patients. The mean pressure of this group is $77,03 \mathrm{cmH}_{2} \mathrm{O}\left(31-120 \mathrm{cmH}_{2} \mathrm{O}\right)$. Only $1(3,23 \%)$ of the observed patients had normal cuff pressure $\left(20-30 \mathrm{cmH}_{2} \mathrm{O}\right)$.

Conclusions. During the study, it was found that the pressure of the endotracheal tube cuff during general anaesthesia at the LSMUL KK Anaesthesiology Clinic does not meet the recommended norm. The majority of patients in the study had higher than recommended cuff pressures.

Correspondence to: siderkev@gmail.com

$$
\text { Gauta 2020-05-05 }
$$

